\title{
ENERGY FOR FUTURE CENTURIES \\ Prospects for fusion power as a future energy source
}

\author{
J. Ongena ${ }^{1}$ and G. Van Oost ${ }^{2}$ \\ ${ }^{1}$ Laboratorium voor Plasmafysica - Laboratoire de Physique des Plasmas \\ Koninklijke Militaire School - Ecole Royale Militaire \\ Association"EURATOM - Belgian State", B-1000 BRUSSELS (Belgium) \\ Partner in the Trilateral Euregio Cluster (TEC) \\ 2 Department of Applied Physics, Ghent University, \\ Rozier 44, B-9000 Gent.
}

\begin{abstract}
The current power consumption and an estimate of the future energy needs of the world are discussed. The present energy supplies and prospects, the possible consequences of a continued massive fossil fuel consumption, and the potential of non-fossil candidates for long-term energy production are outlined. An introduction to the potential contribution of future fusion reactors is given. The resources, safety, environmental and economic aspects of magnetic fusion energy are discussed.
\end{abstract}

\section{INTRODUCTION}

Mankind currently has an addiction to fossil fuels which is non sustainable and dangerous for several reasons: (i) burning of fossil fuels is having a measurable impact on our atmosphere and could trigger serious changes in climate (ii) much more interesting use could be made from this resource (iii) they will run out at some point.

The number of conceivable non-fossil candidates which in the long-term could substantially contribute to energy production is very limited: renewables, nuclear fission and fusion. Fusion is the least developed of the three, but has particularly valuable environmental and safety advantages and has virtually inexhaustible resources.

Before starting the discussion let us briefly discuss some of the basic physical quantities used in this paper. Energy is the capacity for doing work by any system and its $\mathrm{SI}$ unit is Joule. Power is the amount of energy produced, transferred, or used per unit of time and its SI unit is Joule per second or Watt. Other units often used to express an energy quantity are e.g. kWh, MWd, TWyr etc. Energy (or power) in the form that it is first accounted for i.e. before any conversion to secondary or tertiary forms of energy (or power) is called primary energy (or power). Energy has several forms, some of which can be changed to another form useful for work. According to the second law of thermodynamics, each thermal conversion process is associated with losses. This is especially true when using a heat flow from a hot source to a cold sink in the conversion process: only a fraction of the heat can be converted in that way into work, the amount depending on the difference in temperature between the hot source and cold sink (Carnot cycle). This difference becomes very clear in discussions on electricity production, where the efficiency is often as low as $30 \%$, and thus a distinction has to be made between thermal power and electrical power (indicated in this paper by the suffix "el").

\section{THE WORLD ENERGY PROBLEM}

\section{II.A. CURRENT AND FUTURE ENERGY NEEDS.}

\begin{tabular}{|l|c|}
\hline \multicolumn{1}{|c|}{ COUNTRY } & $\begin{array}{r}\text { PER CAPITA POWER } \\
\text { CONSUMPTION IN 2010 } \\
(\mathrm{kW})\end{array}$ \\
\hline \hline United Arab Emirates & 21.35 \\
Iceland & 20.00 \\
Qatar & 19.30 \\
Kuwait & 15.20 \\
Bahrain & 14.20 \\
Norway & 12.00 \\
Canada & 11.50 \\
USA & 9.50 \\
Australia & 8.10 \\
Belgium & 7.90 \\
The Netherlands & 7.70 \\
Russia & 6.20 \\
South Korea & 6.60 \\
Japan & 5.10 \\
Germany & 5.10 \\
Europe of 27 & 4.10 \\
South Africa & 3.40 \\
China & 2.30 \\
Brazil & 1.75 \\
Vietnam & 0.62 \\
India & 0.56 \\
Zimbabwe & 0.42 \\
Mozambique & 0.24 \\
Congo (Kinshasa) & 0.05 \\
Chad & 0.01 \\
World & 2.23 \\
\hline
\end{tabular}

Table I Per capita total primary power consumption for selected countries (total annual primary power consumption per country divided by the number of its inhabitants [1,2])

Table I gives an overview of the total primary power consumption per capita for different regions in 
the world. This is the equivalent amount of power consumed per person 24 hours a day, 365 days per year. It is interesting to note that the largest consumers are often to be found among those countries which are also large energy producers and exporters (Qatar, Bahrain, Kuwait, etc) or dispose of cheap and abundant energy (Iceland, Canada, etc...). Lowest consumption is found in developing countries. Outstanding is also the difference between the USA and the Japanese or European average power consumption: about twice as much power is used for essentially a comparable standard of living.

With over 7 billion people in 2011 and a primary power consumption per capita (world average) of about $2.2 \mathrm{~kW}$, the total amount of energy currently consumed in the world is about $2.2 \mathrm{~kW} \times 7$ billion people $\times 1$ year $\cong 15.4$ TWyr. An estimate of what might be needed in the future can be found with the following two assumptions:

(i) primary power consumption per capita (world average) will increase by $800 \mathrm{~W}$ from $2.2 \mathrm{~kW}$ to about $3 \mathrm{~kW}$ (i.e. about half of what is already used in Europe and one fourth of what is currently used in the USA), and

(ii) world population will rise to about 10 billion in the next 50 years, (medium variant prediction) by the UN [3] (see also Fig. I)

Thus, in 50 years we expect the world to consume yearly an amount of primary energy equal to $3 \mathrm{~kW} \times 10$ billion people $\times 1$ year $=30$ TWyr or about two times more than what is consumed now!

The first assumption fits with energy data from the past decades: in the last 25 years (1980-2006), the primary power consumption per capita (world average) has increased by about 300W (associated with an increase in total primary energy consumption in the world by about 66\%). Extrapolating linearly (if justified) would amount to $600 \mathrm{~W}$ in 50 years.

Another confirmation comes from the study of the World Energy Council and the International Institute for Applied System Analysis [4], which considers three different scenarios for the future development of the world energy consumption: (i) a high growth scenario with impressive technological developments and high economic growth [Case A], (ii) a "middle course" scenario with less ambitious and perhaps more realistic technological improvements and a more intermediate economic growth [Case B] and (iii) an ecologically driven scenario which represents a "rich and green" future, both with substantial technological improvements, strict environmental control mechanisms and an unprecedented international collaboration for environmental protection [Case C]. The predicted energy future for the three scenarios described above is shown in Fig. I. The middle course scenario, Case B, considered as the most realistic scenario, predicts about 25TWyr for 2050, close to the estimate above.
Note that the numbers above would imply that we need an additional power production capacity (for electricity, direct heating, transportation, etc) of about 15 TW in the next 50 years. If true, this means $300 \mathrm{GW} /$ year, or equivalently a capacity of $1 \mathrm{GW}$ nearly every day for the next 50 years. Taking into account that on top of this, old power or heat generation systems will have to be replaced (also amounting to about 15TW), a total of 30GW greener power systems has to be constructed in the next 50 years. This clearly shows the staggering task that lies in front of us. We can only hope that this will indeed be greener systems, but unfortunately and as will be shown in what follows, there are currently not sufficient clean alternatives ready to replace fossil fuels on such a large scale.

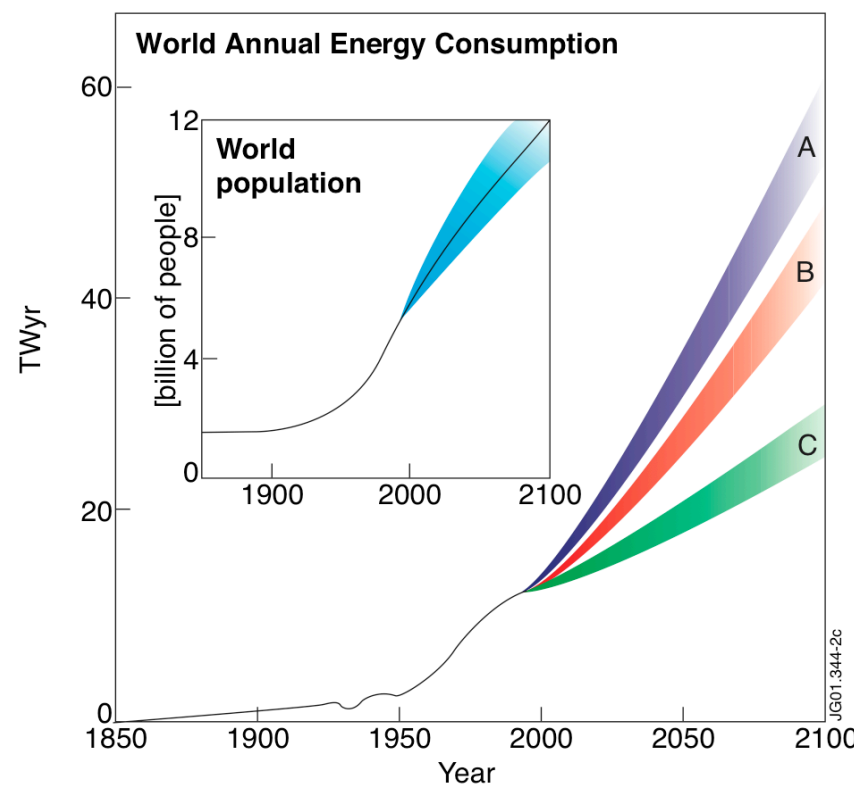

Fig. I Past and projected evolution of the annual world primary energy consumption according to three different scenarios, as documented in [4]. The inset shows the projected evolution of the world population [3]. The bands reflect the uncertainties in the predictions.

What is then the best way forward? As we will see below, there is no simple answer to this question.

\section{II.B. CURRENT ENERGY SUPPLY AND FUTURE PROSPECTS}

An overview of the present proved recoverable reserves for various energy options is given in Table II, together with an estimate of the period still available for use at the current rate of consumption.

In addition, one has to be careful with these numbers, as huge political and economic interests (for a frightening example, see [5]) might lead to underor overestimates depending on who is providing the data. In addition, future prospection could result in updates of these numbers. It is clear from Table II that we can indeed go on for at least a few decades. 


\section{But is this really desirable?}

As can be seen in Table III, about $90 \%$ of our energy is currently produced by burning fossil fuels This could pose serious problems in the future.

\begin{tabular}{|l|l|l|}
\hline FUEL & $\begin{array}{l}\text { PROVED } \\
\text { RECOVERABLE } \\
\text { RESERVES } \\
(2009)\end{array}$ & $\begin{array}{l}\text { YEARS OF USE AT } \\
\text { THE CURRENT } \\
\text { RATE OF } \\
\text { CONSUMPTION }\end{array}$ \\
\hline \hline Coal & $\begin{array}{l}0.910^{12} \text { tons } \\
\text { Crude oil }\end{array}$ & 210 \\
Natural gas & $19010^{12}$ barrels & $30-40$ \\
Uranium (ore) & $4.710^{6}$ tons & $\begin{array}{l}80-70 \\
85-270^{*} \\
(2600-8000)\end{array}$ \\
$\begin{array}{l}\text { Uranium } \\
\text { (sea water) }\end{array}$ & $4.510^{9}$ tons & $81000-260000$ \\
\hline \multicolumn{2}{|c|}{ * assuming Light Water Reactor, once through } \\
** if breeder technology is employed.
\end{tabular}

Table II Years of use of different fuels at the current rate of consumption [1,2,6-9]

First, depletion of the world energy resources will inevitably lead to political instabilities (and has already caused tensions) in the world. The energy crisis of the 1970's, the Iraq war in the 1990s, etc. are small reminders of what we could face. Note that more and more institutions are warning about peaking of conventional oil reserves $[10,11]$ with possible shortages and/or price increases in the near future. The oil peak discussion is complex: different concepts of "reserves" are often used, changes in price could have big influences on the economical recoverability of a source, financial speculation can interfere etc. Moreover, there are very large in-place resources of both conventional and various non-conventional oils (primarily tar sands and shale oil). But many analysts calculate that once conventional oil peaks, it will be difficult to bring these other resources on-line fast enough to offset the decline in the production of conventional oil. These and various other facets of this discussion are documented in ref [12]. However, it should be clear that much better use could be made of these finite resources. They are invaluable for our chemical and pharmaceutical industry. From this point of view, our present energy production scheme causes irreplaceable basic chemicals to be literally 'going up in smoke' and thus lost forever on a gigantic scale.

The second, and most worrisome problem is the possible inluence to our environment of the massive use of fossil fuels due to the inevitable release of gigantic quantities of $\mathrm{CO}_{2}$. In 2012 alone, about 32 billion tons of $\mathrm{CO}_{2}$ were released in the atmosphere [1]. This could still seem to be negligible, as it represents only a minor fraction of the total amount of $\mathrm{CO}_{2}$ released (and subsequently recycled) by nature. But precisely because these natural flows balance out, any additional source of $\mathrm{CO}_{2}$ will lead to an increase. This is exactly what is observed: a steep increase of the $\mathrm{CO}_{2}$ content in the atmosphere during the last few decades, as illustrated in Fig. II. This graph - compiled from analysis of air bubbles in the ice of the Antarctic and air samples at the top of the Mauna Loa mountain on Big Island (Hawaii) - compiled data up to 1996. It shows clearly the ever faster increase in $\mathrm{CO}_{2}$ since the beginning of industrialisation around 1800. The out of graph star in Fig II indicates the current level (2013) of 400ppm [13] and illustrates the increase of $40 \mathrm{ppm}$ that took place over the last 17 years. Comparing this with the previous period it took for a similar increase in $\mathrm{CO}_{2}$, about 70 years from 1930 to 1996 - it shows that we are far from curbing $\mathrm{CO}_{2}$ emissions.

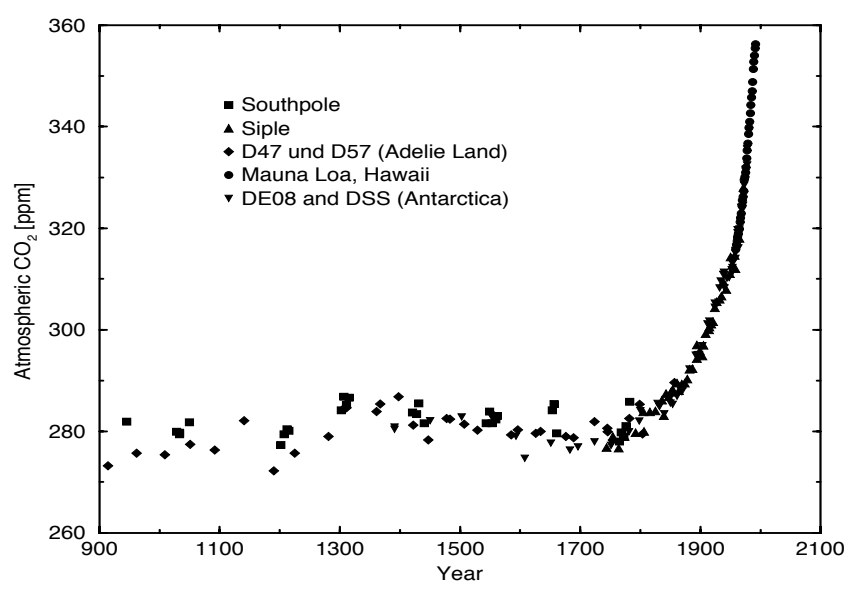

Fig. II Evolution of the $\mathrm{CO}_{2}$ concentration in the atmosphere (in ppm) during the last 1000 years up to 1996 [14]. The out of graph black star added at the top right of the figure indicates current $\mathrm{CO}_{2}$ levels (2008, 385ppm [13]).

Note also that all this $\mathrm{CO}_{2}$ has accumulated in about 200 years. This is very short on a geological time scale and rather frightening in view of additional evidence that the $\mathrm{CO}_{2}$ concentration has remained at about $280 \mathrm{ppm}$ for the last 160000 years [15]. Carbon sequestration or carbon capture and storage (CCS) could perhaps help to reduce future $\mathrm{CO}_{2}$ increases [16], but is of no use to decrease present atmospheric levels.

What are the possible consequences of such a sudden change in the composition of the atmosphere?

$\mathrm{CO}_{2}$ is a greenhouse gas, and a higher concentration of this gas will lead to an increased absorption in the atmosphere of the infrared radiation re-emitted by the earth. This has lead to a continuous increase in the mean global temperature in past years. The consequences are becoming visible, e.g. the last decade being the warmest since early $1800[15,17]$ and effects in Greenland, on glaciers worldwide and 
polar ice are very impressive (see e.g. ref. [18] for truly frightening examples) and do raise serious concern. To what will all this lead on the long-term? The answer to this question is not evident, because our ecosystem is very complex, with many feedback channels, some of them still partly or fully unknown and thus impossible to take correctly into account in modelling. Some buffering against changes probably exists, but there are surely limits to the adaptability of our ecosystem and two main questions are: what are these limits, and in which direction will the ecosystem evolve as soon as the stability thresholds are crossed? We should also not forget that the climate system is inherently unstable: climate records from the past have indicated that variations of more than $7{ }^{\circ} \mathrm{C}$ have taken place in the average sea water temperature in the course of a few tens of years [19].

\begin{tabular}{|l|c|}
\hline PRIMARY ENERGY SOURCE & $\begin{array}{l}\text { CONTRIBUTION TO } \\
\text { PRIMARY ENERGY } \\
\text { PRODUCTION (2008) }\end{array}$ \\
\hline \hline Oil & $33.7 \%$ \\
Coal & $23.8 \%$ \\
Gas & $29.6 \%$ \\
Fission & $5.2 \%$ \\
Hydro-electricity & $6.4 \%$ \\
Solar, wind, wood, waste,... & $1.3 \%$ \\
\hline
\end{tabular}

Table III Contribution of different primary energy sources to the primary energy production in the world [8].

What makes things even more frightening is that the excess $\mathrm{CO}_{2}$ decays exponentially with a very long time constant (100-200 years), mainly determined by the slow exchange of carbon between surface waters and the deep ocean [15]. This means also that as soon as changes are visible in our climate, we will have to deal with these effects for very long times, even if we could shut down all sources of $\mathrm{CO}_{2}$ immediately. Even worse, returning to previous levels is no guarantee neither as it cannot be ascertained that the whole ecosystem will return in a reversible way to the previous situation once critical (unknown!) thresholds have been crossed.

This is the most threatening consequence of our energy production scheme nowadays. We are conducting a possibly irreversible large-scale geophysics experiment. We have to remember that we have only one atmosphere and that it is irreplaceable, in other words, we are all "sitting in the test tube". It cannot be excluded that certain parts of the world could become no longer inhabitable due to rising sea levels or desert formation; in addition, food-producing areas could shift, with hunger, poverty, migration of people, etc. as possible consequences. This would constitute a serious threat to peace and international security.
Is this the prospect we would like to offer our children and grand children?

In this context, it seems nearly unavoidable to reduce or stop burning fossil fuels and try to use other energy sources as soon as possible. It seems also unwise to use uncertainties in the predictions for future climate change as an excuse for delaying necessary actions. The only thing we are left with currently is to try to limit the impact (see [15]) and thus one of the consequences could be environmentally imposed reductions on the use of fossil fuels, well before the effects of resource limitations are felt. But this can only be realistically imposed if there are sufficient non-fossil alternatives. To make things worse, efforts to reduce emissions of greenhouse gases may be alone insufficient to avert unacceptable levels of climate change. Therefore geoengineering methods (e.g. increasing the albedo of the earth by injecting aerosols in the stratosphere) are beginning to be considered as a possible option to "keep the earth cool" (see e.g. [20, 21]). It underlines very clearly that there is 'no easy fix' to the problems we are facing.

There are only two classes of long-term alternatives to burning fossil fuels: renewables and nuclear energy (fission and fusion).

However, there should be no illustions that bringing on-line massive quantities of non-fossil solutions will take time. It should be done wisely and with vision, and with respect for scientific and economic realities. Unfortunately, except for fission, none of the possible alternatives at present is sufficiently mature (see Sect. II.C); but even fission is (i) only short term with the current type of reactors (implying the need for breeder technology, unless one could use seawater extraction [6], see below) and (ii) has a low level of acceptance by the general public. A revival of nuclear energy seems a necessity, but it will still take a while before a large-scale increase can be realised. Fear of nuclear energy is often misused as a 'source of votes' from a general public that is in many cases very badly informed. Political decisions also often backfire (and the public is left uniformed): in the case of Germany, closing down 7 nuclear plants in the aftermath of Fukushima has led to a $7 \%$ increase in $\mathrm{CO}_{2}$ production, despite really enormous investments ( 10-12 billion Euro/year for the last 10 years) in green energy systems. The low quality of the public discussion, frequently lacking reference to realistic numbers or using the numbers very selectively, is a matter of serious concern and correct and neutral education of the general public is an absolute necessity. To make things worse, there are strong economic and political powers trying to maintain the current situation by all possible means, see e.g. the frightening report in Ref. [5].

\section{II.C. LONG-TERM NON-FOSSIL ENERGY SOURCES}

Although renewable energy resources in the world are large and inexhaustible, they have, unfortunately, only a limited potential [22]. Natural obstacles met by renewables are low energy density 
and/or fluctuations in time, implying the need for storage, which reduces again the efficiency and leads to extra costs.

A useful insight in this respect can be gained from a very simple example on hydropower, at this moment the most important renewable energy source. The energy needed to boil 1 liter of water (from 0 to $100 \mathrm{C}$ ) is equivalent to the energy gained from 100 liters of water falling over $426 \mathrm{~m}$ (nearly half a $\mathrm{km}$ ) assuming complete conversion of gravitational potential energy into heat. Two important conclusions follow immediately: (i) we consume a lot of energy without realizing, (ii) it requires a large effort to extract these amounts from sustainable sources.

\begin{tabular}{|c|c|c|}
\hline $\begin{array}{l}\text { RENEWABLE } \\
\text { CATEGORY }\end{array}$ & $\begin{array}{l}\text { RENEWABLE } \\
\text { SOURCE }\end{array}$ & $\begin{array}{l}\text { POWER } \\
\text { OUTPUT } \\
\left(\mathrm{W} / \mathrm{m}^{2}\right)\end{array}$ \\
\hline \multirow{7}{*}{ Sun based } & Solar heating & 53 \\
\hline & $\begin{array}{l}\text { Concentrating solar } \\
\text { power (deserts) }\end{array}$ & 15 \\
\hline & Solar photovoltaics & $5-20$ \\
\hline & Solar chimney & 0.1 \\
\hline & Ocean thermal & 5 \\
\hline & Wind & $2-3$ \\
\hline & $\begin{array}{c}\text { Waves } \\
\text { (Pelamis farm) }\end{array}$ & 30 \\
\hline \multirow{3}{*}{$\begin{array}{l}\text { Gravitation } \\
\text { based }\end{array}$} & Tidal power & 6 \\
\hline & Tide pool & 3 \\
\hline & Hydro-electricity & 11 \\
\hline \multirow{5}{*}{$\begin{array}{l}\text { Agriculture } \\
\text { based }\end{array}$} & Biogas & 0.02 \\
\hline & Rape seed oil & 0.13 \\
\hline & $\begin{array}{l}\text { Bio-ethanol } \\
\text { (sugar cane) }\end{array}$ & 1.2 \\
\hline & Energy crops & 0.5 \\
\hline & & $0.1-0.2$ \\
\hline $\begin{array}{l}\text { Earth } \\
\text { based }\end{array}$ & Geothermal Heat & 0.017 \\
\hline
\end{tabular}

Table IV Power production per $m^{2}$ of land or sea surface occupied. Renewable energy is rather diffuse, leading to large, countrysized facilities in order to contribute substantially (from [22]).

The potential of renewables is further illustrated in Table IV compiling values for the power output per unit land or sea area occupied for a number of possible options. Best solutions seem solar heating, wave power, concentrated solar power and hydro electricity. These numbers can be put into context by comparing with the power output per $\mathrm{m}^{2}$ of a large $(1000 \mathrm{MW}, \mathrm{el}) \mathrm{coal}$ or nuclear power plant $\left(\sim 150 \mathrm{~kW} / \mathrm{m}^{2}\right)$ or the surface of the lake behind a dam $\left(>100 \mathrm{~km}^{2}\right)$ to provide $1000 \mathrm{MW}$, el.

Renewable and nuclear energy systems have the common feature that emissions of greenhouse gases and other atmospheric pollutants are 'indirect', that is, they arise from stages of the life-cycle other than power generation. In the case of nuclear energy, this arises mainly from mining and processing ore, and is only a minor effect. In the case of renewables, the low power density, illustrated in Table IV, unavoidably implies important land use and/or investment in materials. E.g. in the case of biomass this implies areas of several $1000 \mathrm{~km}^{2}$ even for a relatively low power production of $100 \mathrm{MW}$ and $\mathrm{CO}_{2}$ emissions from fertilizer/pesticide production, harvesting, drying and transportation have to be taken into account. It could lead for some 'low carbon' technologies to an outperformance of their potential to contribute effectively to $\mathrm{CO}_{2}$ reductions. For interesting analysis see $[23,24]$. The production of e.g. solar cells causes quite some pollution if one is not careful, and have already led to protests e.g. in China [22a]. Some of the estimates of the world wide potential also seem not to take into account fundamental restrictions. E.g. in the case of wind energy, a bottom-up estimation seems to easily lead to overestimations [22b]. For a very interesting discussion on sustainability, energy efficiency and subsidies see [22c]; a critical assessment of the consequences of the recent German energy policy is given in [22d]. These and other arguments should be carefully taken into account in discussing energy options.

We would like to stress that we do not mean to imply that renewables are useless. The purpose is to point out important aspects of renewables that should not be forgotten in discussions on our energy future. Land use and indirect emissions are two of them. It certainly makes sense to try to exploit these as much as is realistically possible, as every non-fossil energy source will be needed in the future. But one should be realistic in assessing their potential [22, 25] to produce energy and effectively reduce $\mathrm{CO}_{2}$ emissions.

The other main non-fossil option is nuclear power generation by fission and for the future, by fusion.

In the case of fission, issues raising concern are waste, safety and proliferation. Concering waste, indeed highly radioactive waste is produced, but the volume is rather low: only about 28 tons of fuel is needed per GWyr,el, resulting in the same amount of irradiated material. (Note that this is less fuel than expected on the basis of $3-4 \%{ }^{235} \mathrm{U}$ enrichment alone, the reason being that about $40 \%$ of the heat is generated from fission of ${ }^{239} \mathrm{Pu}$ and ${ }^{241} \mathrm{Pu}$ formed from ${ }^{238} \mathrm{U}$ by neutron capture). But about 27 tons of the 
irradiated fuel can in principle be reprocessed and reused in other reactors [26] as it consists of a mixture of about $224 \mathrm{~kg} 235 \mathrm{U}, 26400 \mathrm{~kg} 238 \mathrm{U}$ and $170 \mathrm{~kg}$ of fissile $\mathrm{Pu}$ isotopes, the rest - fission products and non-fissile elements - must be disposed of. In essence, only 1 ton or about $50 \mathrm{dm}^{3}$ of highly active waste is produced per GWyr,el. Moreover, with the right techniques this can be handled safely and new methods are being developed to store [27], or even eliminate it by transmutation thereby producing energy [28]. Reprocessing is unfortunately no longer an option for many countries, so the irradiated rods are stored after cooling in special containers. For the Belgian reactors Doel 1 and $2(\sim 830 \mathrm{MW}$,el total) this results in one container per year, still a small volume for the amount of power produced, certainly if compared with greenhouse gases and other pollutants generated by burning fossil fuels. The radiological danger of nuclear power generation should also be put in perspective comparing with coal power plants. Trace elements in coal like thorium and uranium accumulate in the ash and add to the natural background radiation. Comparing radiation doses from airborne effluents of $1000 \mathrm{MW}$,el coal-fired and nuclear power plants and assuming a 1 percent ash release to the atmosphere (Environmental Protection Agency regulation) and 1 part per million of uranium and 2 parts per million of thorium in the coal (approximately the U.S. average), population doses from the coal plant are typically higher than those from pressurizedwater or boiling-water reactors that meet government regulations. [28a, 28b].

With the present reactor types the lifetime of our uranium resources from ore is comparable to that of oil or gas - about 80 years. Using breeder technology to transform non-fissile fuel into fissile elements, we could stretch our resources by a large factor (30 or more $[9,29,30])$ although the safety and environmental problems are potentially more difficult to cope with. Perhaps the need for breeders could be avoided altogether, if uranium extraction from seawater would become an economical option [6].

\begin{tabular}{|c|c|}
\hline METHOD & $\begin{array}{l}\text { ANNUAL } \\
\text { CONSUMPTION FUEL } \\
1000 M W \text {,el. } \\
\text { size of a single large } \\
\text { electric power plant) } \\
\end{array}$ \\
\hline Coal & 2700000 tonnes \\
\hline Oil & 1900000 tonnes \\
\hline Fission & 28 tonnes of $U$ \\
\hline Fusion & $100 \mathrm{~kg} \mathrm{D}$ and $150 \mathrm{~kg} \mathrm{~T}$ \\
\hline
\end{tabular}

Table $V$ Fuel consumption for different energy production methods
Concerinng safety, new reactor concepts, which rely on passive safety systems, will surely contribute to increase public acceptance [31]. In this context, the Tchernobyl incident should be mentioned, as it was not the result of a malfunction under normal working circumstances, but rather due to negligence and total disregard of safety rules. As such it is close to an unbelievable criminal act, a fact hardly ever mentioned by the mass media. The Tchernobyl reactor (RBMK-1000) was of a dangerous design (among others, it has a positive temperature coefficient). All reactors of this type are closed worldwide. The reactor was not protected from the environment (as in the West) by a concrete and steel dome. Worst of all, the accident was triggered by trying out a dangerous and badly prepared experiment. Operators were put under severe pressure from local officials. In the panic of the last minutes, the control system was disabled and all control rods were fully extracted, leaving no room for a fast intervention in case of a runaway reaction. No wonder that under such conditions the worst possible happened. A hair raising and detailed account of the events on 26 April 1986 can be found in e.g. refs. [32, 33].

The recent events in Fukushima, Japan, although very serious, should not be over dramatised, or lead to panic reactions. It should be underlined that the earthquake itself, although of an extremely large magnitude, did lead to a correct and timely shutdown of all nuclear plants in Japan. It was the arrival of a tsunami of enormous proportions that was the major problem and killed an estimated 20000 people. Nobody died so far from the nuclear incident itself. Conclusions should be (and are) drawn on justified critiques of certain aspects of the construction and localization of those damaged Japanese plants. But it seems unwise to plan a complete nuclear shutdown if no good alternative is immediately ready to take over the nuclear share, or if as a result one has to import power from other nuclear nations or end up with an increased dependency on fossil fuels. The danger is also real that due to inappropriate decisions very valuable know-how could get lost for a technology that could serve good purposes in the coming decennia

The other nuclear option is fusion. It is the least developed of the three but it holds the promise of being a safe, inexhaustible and rather clean energy production method. As such it could become the best compromise between nature and the energy needs of mankind. Recent studies carried out for the European Commission [34] confirm this point of view. Energy quality criteria will become most important in the future: energy production must be not only economically, but also environmentally and societally acceptable.

The huge contrast in fuel consumption between fossil and nuclear methods to generate energy becomes clear from a look at Table V. This results of course from the large difference in energy gained from a nuclear reaction compared to a chemical one - per 
reaction a factor of around $10^{6}$ for fission and $10^{7}$ for fusion. The numbers mentioned reflect what is needed for just one electric power plant. A good idea of the gigantic quantities of $\mathrm{CO}_{2}$ released in the atmosphere yearly is found by calculating the equivalent length of a train carrying 2700000 tonnes of coal: it has a length of $540 \mathrm{~km}$, i.e. the distance between Paris and Amsterdam. Per power plant of $1000 \mathrm{MW}$,el and per year, this quantity of coal gets (nearly totally) converted into 10000000 tonnes of $\mathrm{CO}_{2}$. The equivalent of many hundreds of such plants are in operation at present...

There is every reason to be worried for the future, as reflected by the projected numbers of electric power capacity to be installed in the next $\sim 50$ years, estimated by the Indian and Chinese governments [35, 36]. These numbers are respectively equal to $480 \mathrm{GW}$,el and $1500 \mathrm{GW}$,el. In the case of China alone, it is estimated that burning coal will generate half of this number in 50 years. However, to reach this level, China will have to build and put into operation each month at least one new electric power plant with a capacity of $1 \mathrm{GW}, \mathrm{el}$ - fired by coal - and this for the next 50 years... Note that the reality surpasses by far projections: an average capacity of $5 \mathrm{GW}, \mathrm{el} / \mathrm{month}$ (coal, gas) has been installed in China over the period 2003-2007 (see Ref. [1]). Consequences of this massive development are becoming visible: data analysis of water samples indicate that mercury levels in the North Pacific Ocean have risen about 30 percent over the last 20 years, attributed to increases in global mercury atmospheric emission rates from coal burning [37] in Asia. This mercury is now accumulating via fish in the food chain.

\section{NUCLEAR FUSION AS AN ENERGY SOURCE FOR THE FUTURE.}

The development of nuclear fusion as an energy source is one of the most complex scientific and technical tasks ever undertaken for non-military purposes and will still span several human generations. There exist presently two approaches to realise nuclear fusion on earth: inertial and magnetic fusion. Inertial fusion consists of micro-explosions of small

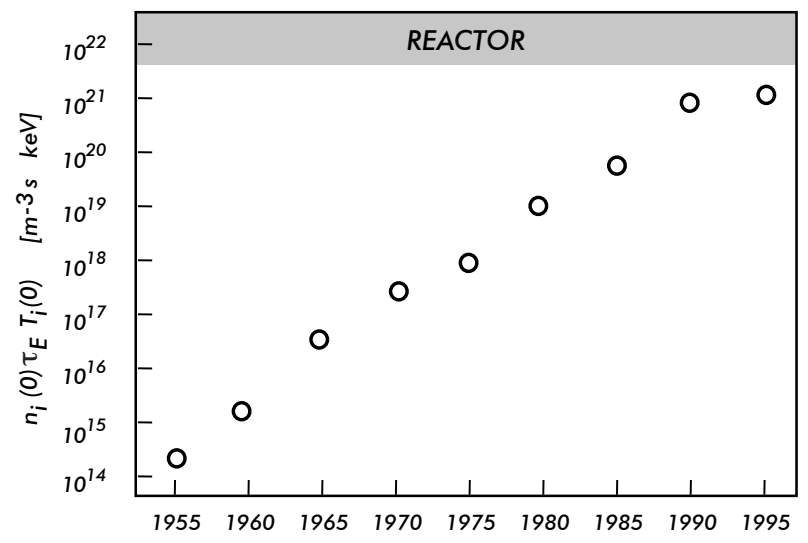

Fig. III Evolution of the value for the fusion triple product since the beginning of fusion research [41] fuel pellets by means of powerful lasers or particle beams. Confinement of the fuel is based on the inertia of the pellet fuel mass, which resists the natural expansion when it is heated to thermonuclear fusion temperatures. Magnetic fusion uses magnetic fields to confine the fuel. The European fusion effort is concentrated on the latter (with tokamaks, stellarators and reversed field pinches) and hence we will briefly review only this method here. The interested reader can find a wealth of additional information in the references $[34,38,39,40]$.

Fantastic progress has been made in magnetic fusion in the last decades. Three generations of tokamaks with doubling of characteristic dimensions at each step led to a 10000 times higher value of the fusion triple product (density times temperature times confinement time) in the last 30 years. Since the start of controlled fusion research, a 10 million-fold improvement in the fusion triple product has been obtained verging to reactor conditions, as illustrated in Fig. III.

Since 1991 several megawatts of fusion power have been released in a controlled way in deuteriumtritium experiments in JET (Joint European Torus, Culham, UK) and TFTR (Tokamak Fusion Test Reactor, Princeton, USA). Peak values of about $16 \mathrm{MW}$ have been obtained on JET in 1997 corresponding to $Q_{D T}$ values (i.e. the ratio of the power released from deuterium-tritium fusion reactions to the power applied to heat the fuel) of more than 0.6; in a stationary way fusion powers of more than $4 \mathrm{MW}$ have been obtained for more than 5 seconds on JET. A comparison of high performance D-T pulses is given in Fig. IV. Break-even in deuterium-tritium experiments, i.e. $\mathrm{Q}_{D T}=1$, is expected at JET in the coming years.

Fusion research entered a new era in 2005 with the international agreement (28 June 2005) on the construction site of ITER at Cadarache (close to Aixen-Provence in France). Construction has started this year (2009), first $\left(\mathrm{H}\right.$ or ${ }^{4} \mathrm{He}$ ) plasmas are projected for 2018 and first D-T plasmas in 2028 [42]. We all look forward to a swift realization of these plans, and hope that they could be realized earlier than planned now the world urgently needs clean energy solutions for the long term!

\section{III.A. NUCLEAR FUSION PROCESSES AND FUTURE FUSION REACTORS}

The least difficult fusion reaction to initiate on earth is that between the hydrogen isotopes $\mathrm{D}$ and $\mathrm{T}$ :

$\mathrm{D}+\mathrm{T} \rightarrow{ }^{4} \mathrm{He}(3.5 \mathrm{MeV})+\mathrm{n}(14.1 \mathrm{MeV})$

in which $D$ stands for deuterium (the stable isotope of hydrogen with a nucleus consisting of one proton and one neutron) and $\mathrm{T}$ for tritium (the radioactive hydrogen isotope with a nucleus of 2 neutrons and 1 proton, see Section III.B). To produce sufficient fusion reactions, the temperature of the plasma has to be on the order of 100 to 200 million C for this reaction. 


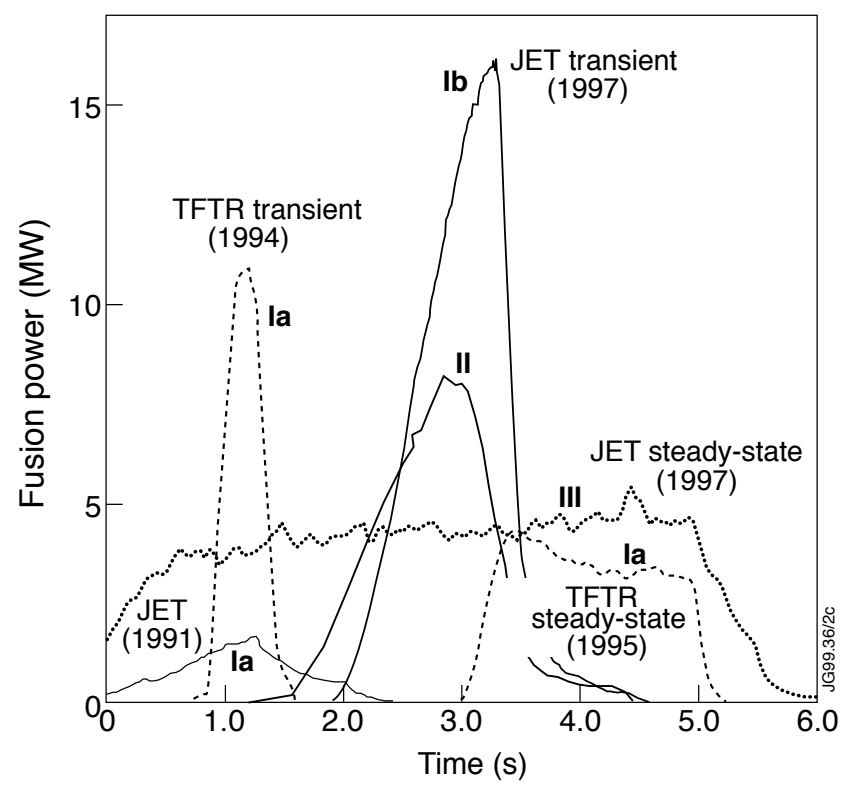

Fig. IV Fusion power development in the $D-T$ campaigns of JET (full and dotted lines) and TFTR (dashed lines), in different regimes: (la) Hot-lon Mode in limiter plasma (Ib) Hotion H-Mode, (II) Optimized shear and (III) Steady-state ELMY-H Modes [43].

A first generation of future fusion reactors would be based on this reaction. The reaction products are thus an $\alpha$-particle (helium nucleus) and a very energetic neutron. Twenty percent of the energy is taken by the $\alpha$-particles that are confined, owing to their charge, and deliver their energy to the background plasma. In this way they compensate for losses and might make the reaction self-sustaining. The kinetic energy of the fast neutrons will be converted into heat in a blanket and then into electricity using conventional technology (steam). About one million times more energy is released from a fusion reaction in comparison with a chemical one (MeV's instead of eV's for the latter). This is the reason why so little fuel can produce so much energy: when burnt in a fusion reactor, the deuterium contained in 1 I of water (about $33 \mathrm{mg}$ ) will produce as much energy as burning 260 I of gasoline.

The D-T reaction is not the only possibility for controlled fusion. Other conceivable reactions are:

$$
\begin{aligned}
& \mathrm{D}+\mathrm{D} \rightarrow{ }^{3} \mathrm{He}(0.82 \mathrm{MeV})+\mathrm{n}(2.45 \mathrm{MeV}) \\
& \mathrm{D}+\mathrm{D} \rightarrow \mathrm{T}(1.01 \mathrm{MeV})+\mathrm{H}(3.02 \mathrm{MeV}) \\
& \mathrm{D}+{ }^{3} \mathrm{He} \rightarrow{ }^{4} \mathrm{He}(3.6 \mathrm{MeV})+\mathrm{H}(14.7 \mathrm{MeV})
\end{aligned}
$$

These are more difficult to achieve and have a much lower power density than the $D-T$ reaction $[40$, 44] but show even more benign environmental features. The D-D reaction would eliminate the need for tritium and produce neutrons with lower energies and are therefore easier to absorb and shield. A reactor based on the $\mathrm{D}^{3} \mathrm{He}$ reaction would proceed with very low neutron production (some neutrons would be produced in competing but much less occurring $D-D$ reactions) with minor radioactivity produced in the reactor structures. This reaction also releases its total energy in the form of charged particles, enabling in principle the possibility of direct energy conversion to electrical energy. However, the prospects for these 'advanced' fuels are still too speculative and only the D-T reaction has immediate future prospects.

\section{III.B. INEXHAUSTIBLE ENERGY SOURCE?}

The most obvious advantage of fusion is the virtual inexhaustibility of the fuels that are cheap and widely accessible. Table VI summarises the presently estimated reserves.

Deuterium, a non-radioactive isotope of hydrogen is extremely plentiful as it can be obtained from ordinary water (about $33 \mathrm{~g}$ from 1 ton) with cheap extraction techniques using conventional technology. Complete burning of deuterons and the first generation fusion products ( $\mathrm{T}$ and ${ }^{3} \mathrm{He}$ ) results in the overall equation:

$$
6 \mathrm{D} \rightarrow 2^{4} \mathrm{He}+2 \mathrm{H}+2 \mathrm{n}+43.3 \mathrm{MeV}
$$

providing $35010^{15} \mathrm{~J} /$ ton $\mathrm{D}$. The deuterium content of the oceans is estimated at $4.610^{13}$ tons [26], thus equivalent to about $5 \times 10^{11}$ TWyr.

Tritium is the radioactive isotope of hydrogen. It decays to ${ }^{3} \mathrm{He}$ by emission of an electron:

$$
\mathrm{T} \rightarrow{ }^{3} \mathrm{He}+\mathrm{e}^{-}+18.7 \mathrm{keV}
$$

with the rather short half-life of 12.3 years. The quantities available in nature are not sufficient for technical applications. The neutrons produced in the fusion reactions will be used to breed it by bombarding a blanket around the burn chamber containing a lithium compound, according to:

$$
\begin{aligned}
& { }^{6} \mathrm{Li}+\mathrm{n} \rightarrow{ }^{4} \mathrm{He}(2.05 \mathrm{MeV})+\mathrm{T}(2.73 \mathrm{MeV}) \\
& { }^{7} \mathrm{Li}+\mathrm{n} \rightarrow{ }^{4} \mathrm{He}+\mathrm{T}+\mathrm{n}-2.47 \mathrm{MeV}
\end{aligned}
$$

Thus the real consumables in the $\mathrm{D}-\mathrm{T}$ fusion process are $\mathrm{D}$ and $\mathrm{Li}$, while $\mathrm{T}$ is an intermediate product burned in the fusion reaction.

Lithium, like deuterium, is a widely available element. There are two isotopes ${ }^{6} \mathrm{Li}$ and ${ }^{7} \mathrm{Li}$, which occur naturally $\left(7.5 \%\right.$ and $92.5 \%$ respectively). ${ }^{6} \mathrm{Li}$ is the most useful isotope as it reacts with neutrons in the lower energy range $(\mathrm{E}<1 \mathrm{MeV})$. Model calculations [34] show that the burn up of ${ }^{7} \mathrm{Li}$ in a future fusion reactor would be negligible and thus only ${ }^{6} \mathrm{Li}$ is relevant to resource considerations. Per ${ }^{6} \mathrm{Li}$ atom, one $\mathrm{T}$ atom is formed, with an extra energy of $4.78 \mathrm{MeV}$. Including the energy released in $\mathrm{D}-\mathrm{T}$ fusion reactions, $22.38 \mathrm{MeV}$ is released per ${ }^{6} \mathrm{Li}$ atom. The energy content of natural $\mathrm{Li}$ is therefore about $2710^{15}$ $\mathrm{J} /$ ton. Estimated reserves of natural $\mathrm{Li}$ are somewhat less than 29 million tons in known ore deposits and 
brines [45] and about 200 billion tons dissolved in sea water (0.1-0.2ppm) [46], equivalent to about $2.410^{4}$ and $1.710^{8}$ TWyr. The amount of energy needed to extract $\mathrm{Li}$ is negligible compared to the energy released in thermonuclear reactions.

\begin{tabular}{|l|l|l|}
\hline FUSION FUEL & $\begin{array}{l}\text { YEARS OF USE } \\
\text { ENERGY } \\
\text { CONTENT } \\
\text { (TWyr) } \\
\text { TO SUPPLY } \\
\text { WORLD } \\
\text { ELECTRICITY } \\
\text { NEEDS (AT } \\
2006 \text { LEVELS) }\end{array}$ \\
\hline \hline D & $5 \times 10^{11}$ & 100 billion yr \\
\hline Li (known reserves) & $2.4 \times 10^{4}$ & 5000 year \\
\hline Li (in sea water) & $1.7 \times 10^{8}$ & 35 million yr \\
\hline
\end{tabular}

Table VI Estimated reserves of fusion fuels $[45,46]$.

Since only one neutron is produced in each fusion reaction and since each new tritium nucleus to be bred from Li requires one neutron, it is necessary to provide a small additional neutron source, to balance losses in the breeding blanket. A possible suitable neutron multiplier is beryllium, using the $(n, 2 n)$ reaction:

$$
{ }^{9} \mathrm{Be}+\mathrm{n} \rightarrow 2^{4} \mathrm{He}+2 \mathrm{n}-1.57 \mathrm{MeV}
$$

Another question related to inexhaustibility is if we dispose of enough suitable materials (e.g. structural and superconducting materials for the magnets) for a large-scale use of fusion energy over many centuries. Also here there seem to be no significant constraints [34]

\section{III.C. SAFETY ASPECTS}

- Inherent and passive safety

- Can Chernobyl-type accidents occur?

First, the amount of fuel available at each instant is sufficient for only a few tens of seconds, in sharp contrast with a fission reactor where fuel for several years of operation is stored in the reactor core. Second, fusion reactions take place at extremely high temperatures and the fusion process is not based on a neutron multiplication reaction. With any malfunction or incorrect handling the reactions will stop. An uncontrolled burn (nuclear runaway) of the fusion fuel is therefore excluded on physical grounds. Even in case of a total loss of active cooling, the low residual heating excludes melting of the reactor structure [34].

\section{- Radioactivity}

The basic fuels ( $\mathrm{D}$ and $\mathrm{Li}$ ) as well as the direct end product $(\mathrm{He})$ of the fusion reaction are not radioactive. However, a fusion reactor will require radiation shielding since it has a radioactive inventory consisting of (i) tritium and waste contaminated by tritium and (ii) reactor materials activated by the neutrons of the fusion reaction. Studies [34, 38, 39] indicate, however, that an adequate choice of the latter can minimise the induced radioactivity such that recycling should become possible after some decades to a century. Thus, radioactivity does not have to be inherent to nuclear fusion, in contrast to nuclear fission where the fission reaction itself leads to dangerous long-lived radioactive products.

The tritium cycle is internally closed, and the total tritium inventory in the fusion power plant will be on the order of a few $\mathrm{kg}$, of which only about 200 grams could be released in an accident. Special permeation barriers will have to be used to inhibit discharge into the environment of tritium diffusing through materials at high temperature [34]. As tritium is chemically equivalent to hydrogen, it can replace normal hydrogen in water and all kinds of hydrocarbons. It could thus contaminate the food chain when released in the atmosphere. The absorption of tritium contaminated food and water by living organisms is a potential hazard. However, possible damage is reduced owing to the short biological half-life of tritium in the body of about 10 days.

\section{- Links to nuclear weaponry?}

The operation of pure (i.e. non-hybrid) fusion reactors (see Section III.E) is not accompanied by the production of fissile materials required for nuclear weapons. Only a significant modification of the fusion reactor - the introduction of a special breeding section containing fertile material - would make the production of weapons grade fissile materials possible. However, according to the conclusion of experts (see e.g. [47]), the presence of such a section (in an environment where none at all should be present) could be easily discovered by qualified inspectors. This is in sharp contrast to a fission reactor where production of these materials occurs in the reactor core itself and where in addition a delicate balance has to be made of large inventories of ingoing and out coming nuclear material to discover any possible diversion of fissile material.

\section{- Other non-nuclear risks}

Reactor designers will have to minimise non-nuclear risks such as Li-fires, release of chemical toxins like $\mathrm{Be}$, sudden loss of vacuum or cooling liquids, etc... But none of the possible issues currently appear to be sufficiently serious to weigh importantly in societal discussions about the attractiveness of fusion compared to other energy systems. 


\section{III.D. ENVIRONMENTAL ASPECTS}

\section{- Environmental pollution?}

The primary fuels ( $\mathrm{D}$ and $\mathrm{Li}$ ) and the direct end product $(\mathrm{He})$ are not radioactive, do not pollute the atmosphere, and do not contribute to the greenhouse effect or the destruction of the ozone layer. Helium is in addition chemically inert and very useful in industry. There are no problems with mining (Li) and fuel transportation. No ecological, geophysical and landuse problems exist such as those associated with biomass energy, hydropower and solar energy.

Measures for tritium containment and detritiation of substances contaminated with tritium will have to be taken. During normal operation the dose for the public in the neighbourhood of the plant will only be a fraction of the dose due to natural radioactivity.

\section{- Dangerous waste?}

An important advantage of fusion is the absence of direct radioactive reaction products, in contrast to fission, where radioactive waste is unavoidable since the products of the energy releasing nuclear reaction are radioactive.

Adequate disposal of radioactive waste is especially difficult if the products are volatile, corrosive or long-lived. The neutron-activated structural materials of a fusion reactor would not pose such problems and because of their high melting point and their low decay heat, will not necessitate active cooling during decommissioning, transport or disposal. Recent studies [34] show that over their life time, fusion reactors would generate, by component replacement and decommissioning, activated material similar in volume to that of fission reactors but qualitatively different in that the long-term radio toxicity is considerably lower (no radioactive spent fuel).

Fusion could be made even more attractive by the use of advanced structural materials with low activation as e.g. vanadium alloys or silicon carbides. These materials offer in principle the prospect of recycling after about 100 years after shutdown of the reactor as the radioactivity would fall to levels comparable to those of the ashes from coal-fired plants [34] (which contain always small amounts of thorium and other actinides). It is not yet clear if they will meet a number of technical specifications with regard to thermo-mechanical properties and the ability to withstand a high neutron flux and further research is necessary to clarify these points [48]. But even if existing structural materials like stainless steel are used, the induced radioactivity in a fusion reactor is still about 10 times less than in a fission reactor of comparable power [29, 39].

\section{III.E. ECONOMIC ASPECTS}

\section{- Economic viability of future fusion plants?}

It is obviously difficult to estimate with any useful precision the cost of a system that will only be put into service several decades from now. In comparison with other energy sources, environmental and safety-related advantages and the virtual inexhaustibility of the fuel sources should be taken into account, as well as the evolution of the cost of electricity based on (exhaustible) resources. Present studies, embodying many uncertainties, produce cost estimates, which are close to those of present power plants. Investment costs (reactor chamber, blanket, magnets, percentage of recirculating power...) will probably be higher, but the fuel is cheap and abundant. Fusion is likely to be a centralised energy source. On the basis of present knowledge, technologically sophisticated power plants will probably have an electrical output larger than $1 \mathrm{GW}$ to be economic. The fast neutrons produced in the D-T reaction could be used to produce fissile material in fusion-hybrid breeder reactors [40]. This complementary role for fusion might improve system economics compared with pure fusion systems; however, it would increase societal concerns related to safety, environment and weaponry.

\section{- Cost of fusion research?}

Public expenditure on fusion research in the European Community is presently about 500 million Euro per year. Every comparison unavoidably has its disadvantages, but in the case of fusion - being an important possible option for our energy future, generating electricity - it seems fair to compare this number to (i) the present cost of electricity in Europe and (ii) to the investments in other energy systems under development.

Concerning (i): The total electricity bill spent in 2006 in the European Community by end users can be estimated as the product of the net consumption times an average electricity price or roughly $3.310^{9}$ $\mathrm{kWh} \times 0.1 \mathrm{Euro} / \mathrm{kWh}=330$ billion Euro [1]. The fusion effort in Europe is thus equivalent to about $0.3 \%$ of the yearly European electricity bill. Alternatively one can calculate the cost of fusion research per European citizen: with over 400 million Europeans, the fusion effort comes down to about 1 Euro for every European per year.

Concerning (ii): All funds for fusion research are and have to be public, due to the long period still needed before a fusion reactor can become a commercially available system. These public funds are very well known. For the other energy sources (especially wind and solar), it is not so easy to get a complete picture of the money spent on research as several private companies are contributing with own research investments. In addition, subsidies or tax reductions may be applied to promote these systems, which should be included in the public expenditure on 
the system. To illustrate these points and to show that the public expenditure on energy research for the other sources is certainly not less than for fusion, we take the case of Germany. Total investments in fusion research currently are about 150 millions Euro / yr. This number should be compared to the cost alone of subsidising/investing in renewables in Germany in the last 10 years, which is estimated at about 120 billion Euro... [49].

\section{CONCLUSIONS}

In a most profound sense, mankind's quality of life depends on an acceptable response to the continually rising demand for energy. To be able to satisfy our future energy needs, we therefore have to invest in all viable energy options, compatible with our environment.

Fusion is one of these options and is characterised by exclusive properties, some of which represent distinct advantages over the other major energy sources. They can be grouped around three aspects:

- Fuel: abundant supply of cheap fuels ( $D$ and $\mathrm{Li}$ ); they are non-radioactive, and their extraction does not cause any significant ecological problem.

- Safety: fusion reactors offer inherent, passive safety. They are not based on a neutron multiplication reaction and do not contain a large supply of fuel in their core. An uncontrolled burn of the Chernobyl type is excluded.

- Environment: Fusion reactions produce energy and no direct radioactive waste. However, in current fusion reactor concepts there is radioactivity from two sources. First, from tritium, which is bred locally from lithium, but consumed directly. Second, by activation of reactor structures by neutrons. Future reactor concepts might strongly limit this radioactivity. Anyhow, by carefully choosing structural materials, the radioactive waste will not constitute a burden for many generations. In addition there is no production of combustion gases. Hence, there is no contribution to the greenhouse effect, to acid rain and to the destruction of the ozone layer.

There should be no illusions about the technical difficulty or the time required bringing even the D-T reaction to a commercially viable system. However, there is no indication up to now to doubt that fusion could be made practical and successful. History has repeatedly proven that major technological projects (not hampered by scientific limits) have finally reached a breakthrough. Who would have believed 80 years ago that highly sophisticated planes would provide transport of passengers across the Atlantic on a large scale and at prices far below those by ship?

Given the potential advantages of nuclear fusion compared to the risks and dangers of all other alternatives for base load electricity generation and given its potential contribution to long-term sustainable world development, is it not our duty towards future generations to continue the fusion effort without delay and with full commitment?

\section{ACKNOWLEDGEMENTS}

Many thanks to Dr.D.Bartlett, Prof.R.Bentley, Dr.A.Pritchard and Ir.K.Mertens for interesting discussions and feedback to this paper. Ms. P.Hickmott is thanked for the careful perusal of the manuscript.

\section{FURTHER READING}

1. David JC MacKay, "Sustainable Energy - without the hot air", UIT Cambridge UK (2009), ISBN 978-09544529-3-3. Also freely downloadable from www.withouthotair.com. This book provides clear physical arguments on the potential of main renewable alternatives. It is a unique book, with a lucid and didactic style, ideal to prepare (e.g.) an energy discussion with the general public, politicians, policy makers and pressure groups. Very strongly recommended.

2. Bernard L.Cohen, "The nuclear energy option", Plenum Press, New York and London (1990). ISBN-13: 978030643567. A superb and still very actual reference containing a clear and very well documented scientific discussion on all aspects of energy production by nuclear fission. Online at: www.phyast.pitt.edu/ blc/book/BOOK.html

3. John H.Fremlin, "Power Production: What are the risks" Adam Hilger, Bristol and New York (1989), ISBN 0-85274-133-2. A very interesting reference on the risks involved in energy production by renewables, nuclear and fossile burning.

4. Douglas R.O.Morrison, "World Energy and Climate in the Next Century", in Proc. of the $24^{\text {th }}$ Session of the International Seminar on Nuclear War and Planetary Emergencies, Erice (Italy) - August 19-24, 1999, pp.347-387. World Scientific Publishing Co, Singapore (2000), ISBN 981-02-4362-6. A very detailed reference dealing with many issues on energy production, now and in the future.

5. Thomas E.Graedel, Paul J.Crutzen "Atmosphere, Climate, and Change", Scientific American Library, W.H.Freeman and Co, New York and Basingstoke 1997, ISBN-13: 9780716750499. An excellent reference dealing with many aspects of world climate in the past and the difficulties to predict future climate.

6. Kenneth.S.Deffeyes, "Hubbert's peak: The impending World Oil Shortage (New Edition)", Princeton University Press (2009), ISBN13: 978-0691-14119-0. A clearly written overview of the current status and future evolution of world oil production, for the general public. This important book with its shocking predictions by a geologist and Princeton University professor specialized in petroleum prospection is not easy to dismiss. Highly 
recommended. The 2001 Edition got the Honorable Mention of the Association of American Publishers for Best Professional/Scholarly Book in Geography and Earth Science

7. Vaclav Smil, "Energy at the crossroads", The MIT Press, Cambridge, Massachusetts (2005), ISBN-13: 9780262194921. Overview of various energy options for the future, with interesting (and sometimes particular) views on the applicability of various energy systems in the future.

\section{REFERENCES}

[1] "International Energy Annual 2010", US Department of Energy, Energy International Annual (DOE-EIA); see http://www.eia.gov

[2] Statistical Tables from the International Energy Agency, available on http://data.iea.org

[3] "World Population Prospects: the 2008 Revision", United Nations Population Division, data up to 2050 available on http://esa.un.org/unpp/. For estimates beyond 2050 see the long range report on www.un.org/esa/population/publications/longrange2/ Long_range_report.pdf

For an interesting discussion on this subject see the controversial article by M.Singer and the accompanying notes by Jean-Marie Robine, "Vers un monde moins peuplé que les États-Unis", La Recherche, 327, 84-86 (January 2000).

[4] N.Nakicenovic (Editor), Arnulf Grübler (Editor), Alan McDonald (Editor), A. Grubler ,A. McDonald "Global Energy Perspectives", IIASA and World Energy Council, Cambridge University Press 1998, ISBN 0521-64569-7

[5] R.Gelbspan, "The Heat is On: The Climate Crisis, The Cover-up, The prescription", updated edition, Perseus Books, Reading Massachusetts (1998) ISBN13: 9780738200255; original edition reviewed by $\mathrm{T}$. O'Riordan, "Betrayers of a global truth", Nature, 389, 685 (1997).

[6] Masao Tamada, JAEA, in Proc. of the $42^{\text {th }}$ Session of the International Seminar on Nuclear War and Planetary Emergencies, Erice (Italy) - August 19-24, 2009.

[7] "Energy Statistics Yearbook 2006", United Nations, Department of Economic and Social Affairs, New York 2009.

[8] "Statistical Review of World Energy 2009"; see www.bp.com

[9] "Uranium 2005: Resources, Production and Demand", OECD Publishing (2006), ISBN 9789264024250. Read-only available from www.oecdbookshop.org/oecd/display.asp?K=5L9TOF 75B3KC\&DS=Uranium-2005
[10] K.S.Deffeyes, "Hubbert's peak: The impending World Oil Shortage (New Edition)", ISBN-13: 978-0691-14119-0, Princeton University Press (2009)

[11] Richard A.Kerr, "The next oil crisis looms large and perhaps close", Science, 281, 1128-1131 (21 Aug 1998); see also: C.Bond Hatfield "Oil back on the global agenda", Nature, 387, 121 (8 May 1997).

[12] UK Energy Research Centre Study: "Global Oil Depletion" October 2009. See http://www.ukerc.ac.uk/support/tiki-index.php?page= GlobalOilDepletion

[13] Dr. Pieter Tans, NOAA/ESRL (www.esrl.noaa.gov/gmd/ccgg/trends/)

[14] F.Joos, "The Atmospheric Carbon Dioxide Perturbation", Europhysics News, 27, 6, 213-218 (1996).

[15] "Climate Change 2007: Synthesis Report" and related reports. (IPCC Fourth Assessment Report) Core editors R.K.Pachauri and A.Reisinger, Cambridge IPCC, Geneva, Switzerland (2007). Available from: www.ipcc.ch/publications_and_data/publications_ipcc _fourth_assessment_report_synthesis_report.htm

[16] D.Reichle, J.Houghton et al., "Carbon Sequestration, State of the Science", US Department of Energy, Office of Science, Office of Fossil Energy, Washington 1999.

[17] M.Verrall, "Climate group rejects criticism of warnings", Nature, 371, 274 (1994); E.Masood, "New IPCC report set to confirm earlier warming conclusions", Nature, 377, 189 (1995)

[18] Several impressive photo compilations became available recently: (i) "Fragile Earth: Views of a Changing Earth", ISBN-13: 9780061137310, HarperCollins Publishers (2006); a summary is available on the web: www.bartholomewmaps.com/fragile_earth_movie/ind ex.html. (ii) "Extreme Ice Survey" by James Balog, www.extremeicesurvey.org; (iii) "Home" by Yann Arthus-Bertrand, www.home-2009.com/us/index.html

[19] J.F.McManus, G.C.Bond, W.S.Broecker, S.Johnsen, L.Labeyrie and S.Higgins; "High-resolution climate records from the NorthAtlantic during the last interglacial." Nature, 317, 326-329 (1994).

[20] Website of the Royal Society (UK): http://royalsociety.org/document.asp?tip $=0 \& i d=872$ $\underline{9}$

[21] UK Parliamentary Office of Science and Technology, Postnote 327 (June 2009), www.parliament.uk/parliamentary_offices/post/enviro nment.cfm

[22] David JC MacKay, "Sustainable Energy - without the hot air", UIT Cambridge UK (2009), ISBN 978-0- 
9544529-3-3. Also freely downloadable from www.withouthotair.com

[22a] "China: Villagers protest at Zhejiang solar panel plant" BBC News 16 sept 2011, http://www.bbc.co.uk/news/world-asia-pacific14963354

[22b] L. M. Miller, F. Gans, and A. Kleidon, “Estimating maximum global land surface wind power extractability and associated climatic consequences", Earth Syst. Dynam., 2, 1-12, (2011)

[22c] M.Jefferson, "Energy efficiency and sustainability", Proc. of the $44^{\text {th }}$ Session of the International Seminar on Nuclear War and Planetary Emergencies, Erice (Italy) - August 19-24, 2011.

[22d] Frondel, M., Ritter, N., Schmidt, C.M., Vance, C.: "Economic Impacts from the Promotion of Renewable Energies: The German Experience", 'Energy Policy', 38 4048 - 4056 (2010)

[23] M.Kleemann, "Aktuelle wirtschaftliche und ökologische Probleme bei der Nutzung regenerativer Energiequellen", Elektrowärme International, 49, Issue A2, A62-70 (Juni 1991) Vulkan Verlag, Essen 1991.

[24] UK Parliamentary Office of Science and Technology, Postnote 268 (October 2006), www.parliament.uk/parliamentary_offices/post/enviro nment.cfm

[25] M.Fuchs, M.Eingartner, "Grenzen der Nutzung regenerativer Energien", in "Kernenergie und andere Energieoptionen: Nutzen, Risiken, Wirtschaftlichkeit", VDI Berichte, 984, 147-168 (1992); H.Schaefer, "Möglichkeiten und Grenzen der Nutzung regenerativer Energien", in "Zukunft der Energieversorgung - Energie der Zukunft", Ruhrgas AG, Essen (1994).

[26] B.L.Cohen, "High level radioactive waste from light-water reactors", Rev.Mod.Phys., 49, 1-20, (1977); "The Disposal of Radioactive Wastes from Fission Reactors", Sci. Am 236, (6), 21-31 (1977).

[27] G.Collard, R. Andre-Jehan, A. Bonne et al., "The HADES project: an underground demonstration facility for the disposal of high-level waste in plastic clay" in Proceedings of the 3rd European Community Conference on Radioactive Waste Management and Disposal (Luxemburg, 17-21 Sept. 1990), Elsevier Science Publishers, London 1991, 418-436.

[28] C.Rubbia, J.A.Rubio, S.Buono, et al. "Conceptual Design of a fast neutron operated High Power Energy Amplifier", Report CERN-AT-95-44 (ET), Geneva 1995.

[28a] J.P.McBride et al., "Radiological Impact of Airborne Effluents of Coal and Nuclear Plants", Science, 202. no. 4372, 1045 - 1050 (1978). [28b] Scientific America online, see

http://www.scientificamerican.com/article.cfm?id=coa l-ash-is-more-radioactive-than-nuclear-waste\&page $=2$

[29] W.Haefele et al., "Fusion and Fast Breeder Reactors", Report RR-77-8, International Institute for Applied Systems Analysis, Laxenburg, Austria (1977).

[30] S.Krawczynski and W.Krug, "Schnelle Brüter - ihre Technik und ihre Rolle zur langfristigen Energiebedarfsdeckung", Chemie-Technik 8, (4), 135142 (1979); A. Camplani and A. Zambelli, "Advanced nuclear power stations: Superphénix and fast-breeder reactors", Endeavour, New Series, 10, (3), 132-138 (1986).

[31] M.W.Golay and N.Todreas, "Advanced LightWater Reactors", Sci. Am., 262, (4), 58-65 (1990); J. Taylor, "Improved and Safer Nuclear Power", Science, 244, 318-325 (1989).

[32] Richard F.Mould, "Chernobyl Record: The Definitive History of the Chernobyl Catastrophe", IOP, Philadelphia (2000), ISBN 0-7503-0670-X

[33] Grigori Medvedev, "The Truth about Chernobyl", Basic Books, New York (1992), ISBN 0-465-08776-0

[34] I.Cook et al., "Safety and Environmental Impact of Fusion" Report EFDA-S-RE-1, EUR(01) CCE-FU/FTC 8/5 (April 2001);

[35] P.K.lyengar, Proc. of the $24^{\text {th }}$ Session of the International Seminar on Nuclear War and Planetary Emergencies, Erice (Italy) - August 19-24, 1999, pp.156-163. World Scientific Publishing Co, Singapore (2000), ISBN 981-02-4362-6

[36] H.Yu Ping, Proc. of the $25^{\text {th }}$ Session of the International Seminar on Nuclear War and Planetary Emergencies, Erice (Italy) - August 19-24, 2000, pp.331-344. World Scientific Publishing Co, Singapore (2001), ISBN 981-02-4669-2

[37] Elsie M. Sunderland et al., "Mercury sources, distribution, and bioavailability in the North Pacific Ocean: Insights from data and models", Global Biogeochem. Cycles, 23, GB2010, doi:10.1029/2008GB003425 (1 May 2009).

[38] J.P.Holdren et al., "Summary of the report of the senior committee on environmental, safety and economic aspects of magnetic fusion energy", Lawrence Livermore National Laboratory, Report UCRL-53766 (1987)

[39] R.W.Conn et al. "Economic, safety and environmental prospects of fusion reactors", Nucl. Fusion, 30 (1990) 1919.

[40] J.Raeder et al., "Controlled Nuclear Fusion: Fundamentals of its Utilization for Energy Supply", John Wiley \& Sons, New York (1986), ISBN-13: 978047110312 
[41] J.Wesson, "Tokamaks", Third Edition, Oxford Science Series nr. 118, Clarendon Press, Oxford (2004), ISBN-0-19-850922-7.

[42] A.Loarte, Invited Talk at the ITER Session of the EPS Fusion Conference in Sofia (2009)

[43] J.Jacquinot and the JET Team, "Deuteriumtritium operation in magnetic confinement experiments: results and underlying physics", Plasma Phys. Control. Fusion, 41 (1999) A13-A46.

[44] E.Rebhan, "Heisser als das Sonnenfeuer", Piper Verlag, München und Zürich, 1992.

[45] R.Keith Evans, "An abundance of lithium" (July 2008), www.worldlithium.com

[46] R.Keith Evans, "Lithium Reserves and Resources", Energy, 3, 379-385 (1978).

[47] "Status Report on Controlled Thermonuclear Fusion, Executive Summary and General Overview", prepared by the International Fusion Research Council (IFRC), International Atomic Energy Agency, Vienna (1990)

[48] E.E.Bloom, "Structural materials for fusion reactors", Nucl. Fusion, 33, 1879-1896 (1990)

[49] Frankfurter Allgemeine Zeitung, 16 Dec. 1999. 